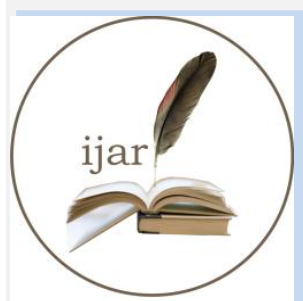

ISSN NO. 2320-5407
Journal Homepage: - www.journalijar.com INTERNATIONAL JOURNAL OF ADVANCED RESEARCH (IJAR)

Article DOI: $10.21474 /$ IJAR01/1361

DOI URL: http://dx.doi.org/10.21474/IJAR01/1361
INTERNATIONAL JOURNAL OF ADVANCED RESEARCH (IJAR)

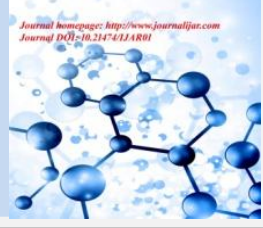

RESEARCH ARTICLE

\title{
SYNTHESIS, CHARACTERISATION AND BIOLOGICAL STUDIES OF METAL COMPLEXES OF THE SCHIFF BASE \{2-[FURAN-2-YL METHYLENEAMINO]PYRIDINE-3-OL\}.
}

\author{
S Mini and *V Sadasivan. \\ 1. Department of Chemistry, University College, Thiruvananthapuram 695034 Kerala, India.
}

\section{Manuscript Info}

Manuscript History

Received: 15 June 2016

Final Accepted: 15 July 2016

Published: August 2016

Key words:-

2-amino-3-hydroxy pyridine, furfural, Schiff base

\begin{abstract}
Five new complexes of $\mathrm{Mn}(\mathrm{II}), \mathrm{Co}(\mathrm{II})), \mathrm{Ni}(\mathrm{II}), \mathrm{Cu}(\mathrm{II}) \& \mathrm{Zn}(\mathrm{II})$ with the Schiff base $\{2$-[furan-2-yl methyleneamino]pyridine-3-ol $\}$ has been synthesized and characterized by elemental analyses, FT-IR, ${ }^{1} \mathrm{H}-\mathrm{NMR}$, Electronic, ESR, Mass spectra, magnetic susceptibility and electrolytic conductance. The Schiff base acts as unianionic bidentate manner with all the metal ions. The metal Schiff base ratio is $1: 1$ in all complexes except in $\mathrm{Ni}(\mathrm{II})$ where it is $1: 2$. The antimicrobial activity of the Schiff base and selected complexes were studied. The result shows that complexes have comparable antibacterial activity with the ligand. The Schiff base and the Mn(II) complex were subjected to antioxidant study.
\end{abstract}

Copy Right, IJAR, 2016,. All rights reserved.

\section{Introduction:-}

Schiff base ligands have been widely studied in the field of coordination chemistry mainly due to their facile synthesis, easy availability and good solubility in common solvents. They are generally known as azomethine compounds due to the presence of azomethine bond (Asiri, et al., 2010).

Schiff bases have wide variety of applications in many fields such as biological, inorganic, analytical, organic and material chemistry. They form stable complexes with transition metals. The studies have shown that complexation of metals to Schiff base ligands improve the biopotentials of the ligands. Several Schiff base ligands derived from pyridine derivatives and their $\mathrm{Cu}(\mathrm{II})$ complexes have also been shown to inhibit tumor growth (Zhao, et al., 2007). Although Schiff bases containing a hetero cyclic moeity have biological activity, the studies on 2-amino-3-hydroxy pyridine Schiff base are less extensive (Raman, N., et al., 2011). 2-amino-3-hydroxy pyridine is of interest since its Schiff bases can act as a bidentate $\mathrm{N}, \mathrm{O}$ donor forming five membered rings.

\section{Materials and methods:-}

High purity grade 2-amino-3-hydroxy pyridine was used in the synthesis. Commercial grade ethanol was purified by standard procedure (Weissberger, A., et al, 1956). An E-merck AR grade sample of methanol was used for conductivity measurements. Infra red spectra were recorded on a Perkin -Elmer infrared spectrophotometer using $\mathrm{KBr}$ pellets in the region $4000-400 \mathrm{~cm}^{-1}$. ESR spectrum of $\mathrm{Cu}$ (II) complex in solution at frozen state was recorded on Varian-E-112 spectrophotometer at X- band using TCNE as reference material. Electronic absorption spectral measurements were recorded in the range 200-900 nm on Perkin Elmer Lamda 25 UV-Visible spectrophotometer. ${ }^{1} \mathrm{H}$ NMR spectrum were recorded on a $400 \mathrm{MHz}$ FTNMR instrument using TMS as reference. The Mass spectra of ligand and the Zn (II) complex were recorded on ESI-FTMS instrument. 
Synthesis of the Schiff base \{2-[furan-2-yl methyleneamino]pyridine-3-ol\} (FAHP):-

An ethanolic solution of 2-amino-3-hydroxypyridine $(5.50 \mathrm{~g}$ in $25 \mathrm{ml})$ and furfuraldehyde $(4.14 \mathrm{ml}$ in $25 \mathrm{ml})$ was boiled under reflux on a water bath for 5-6 hrs. The solution was cooled to room temperature and kept for 24 hrs. A dark green solid separated was filtered, washed with ethanol and recrystallised from DMF. Yield 86\%.

\section{Synthesis of the complexes :-}

The metal complexes have been prepared by mixing ethanolic solution of respective metal salts $\left[\mathrm{Mn}(\mathrm{Ac})_{2} .4 \mathrm{H}_{2} \mathrm{O}\right.$, $\mathrm{Co}\left(\mathrm{NO}_{3}\right)_{2} \cdot 6 \mathrm{H}_{2} \mathrm{O}, \mathrm{NiCl}_{2} \cdot 6 \mathrm{H}_{2} \mathrm{O}, \mathrm{CuCl}_{2} \cdot 2 \mathrm{H}_{2} \mathrm{O}$ or $\mathrm{Zn}(\mathrm{Ac})_{2} .2 \mathrm{H}_{2} \mathrm{O}$ ] with ethanolic solution of the Schiff base FAHP [2(furan-2-yl methyleneamino)pyridine-3-ol] in 1:1 ratio. The reaction mixture was refluxed on water bath for 3-4 hours. The greenish black products appeared on standing the solution were filtered washed with ethanol-water mixture and recrystallised from ethanol and dried over anhydrous $\mathrm{CaCl}_{2}$. The yield obtained was $70 \%$.

\section{Results and discussion:-}

All complexes are stable solids at room temperature and soluble in DMF, DMSO and partially soluble in methanol. The purity of the Schiff base was confirmed by elemental analysis as well as by IR spectral studies. For FAHP the emperical formula was $\mathrm{C}_{10} \mathrm{H}_{8} \mathrm{~N}_{2} \mathrm{O}_{2}$, and the microanlytical values are found to be: $\mathrm{C} 63.3 \%, \mathrm{H} 4.5 \%, \mathrm{~N} 14.7 \%$, against the calculated values: $\mathrm{C} 63.8 \%, \mathrm{H} 4.2 \%, \mathrm{~N} 14.8 \%$. The molar conductance at room temperature was determined using $10^{-3} \mathrm{M}$ solutions of the complexes in methanol and DMF. The values support the non-electrolytic nature for all the complexes (Geary, W.J., 1971). Analytical data of the complexes are presented in Table-1, along with their molar conductance and magnetic moment values.

\section{IR spectral data:-}

The infrared absorption of FAHP at $1557 \mathrm{~cm}^{-1}$ is due to asymmetric stretching vibration of $-\mathrm{C}=\mathrm{N}$ group gets lowered in the complexes within the range $1532-1536 \mathrm{~cm}^{-1}$, indicating the coordination of azomethine nitrogen to metal ion (Rosu, et al., 2010). This is supported by the appearance of new band in the range $482-491 \mathrm{~cm}^{-1}$ to $v_{\mathrm{M}-\mathrm{N}}$. The IR spectrum of FAHP shows the most characteristic band at $3252 \mathrm{~cm}^{-1}$ due to $v_{\mathrm{OH}}$ is absent in the spectra of complexes indicating the deprotonation of the $\mathrm{OH}$ group and its coordination with metal ion. A characteristic band at $1485 \mathrm{~cm}^{-1}$ in the FAHP due to $v_{\mathrm{C}-\mathrm{N}}$ of pyridine has no change in the complexes spectra indicate that the pyridine ring nitrogen does not participate in coordination (Rajendra. K. Jain, et al., 2010). The formation of M-O bond is supported by the appearance of weak bands in the region of $525-530 \mathrm{~cm}^{-1}$ in the spectrum of complexes. The IR spectral data of FAHP and the complexes are given in Table-2.

\section{Electronic spectral data:-}

Electronic spectrum of FAHP recorded in methanol consists of two band maxima at $441 \mathrm{~nm}$ and $230 \mathrm{~nm}$ corresponding to $n \rightarrow \pi^{*}$ and $\pi \rightarrow \pi^{*}$ transitions (Narang, K.K., and Singh V.P., 1993). Cu(II) complex of FAHP shows two bands at 690 and $540 \mathrm{~nm}$ which are assignable to ${ }^{2} \mathrm{~B}_{1 \mathrm{~g}} \rightarrow{ }^{2} \mathrm{~B}_{2 \mathrm{~g}}$ and ${ }^{2} \mathrm{~B}_{1 \mathrm{~g}} \rightarrow{ }^{2} \mathrm{E}_{\mathrm{g}}$ transitions respectively (Rajendra K Jain and Anand P Mishra.,2012). Ni(II) complex of FAHP display three absorption bands at 485, 573 and $805 \mathrm{~nm}$ corresponds to ${ }^{3} \mathrm{~A}_{2 \mathrm{~g}}(\mathrm{~F}) \rightarrow{ }^{3} \mathrm{~T}_{1 \mathrm{~g}}(\mathrm{P})$ and ${ }^{3} \mathrm{~A}_{2 \mathrm{~g}}(\mathrm{~F}) \rightarrow{ }^{3} \mathrm{~T}_{1 \mathrm{~g}}(\mathrm{~F})$ and ${ }^{3} \mathrm{~A}_{2 \mathrm{~g}}(\mathrm{~F}) \rightarrow{ }^{3} \mathrm{~T}_{2 \mathrm{~g}}(\mathrm{~F})$ transitions. This suggests a distorted octahedral structure for $\mathrm{Ni}(\mathrm{II})$ complex (Lever, A.B.P., 1968). The electronic spectrum of the cobalt complex shows three bands at $643 \mathrm{~nm}, 488 \mathrm{~nm}$ and $441 \mathrm{~nm}$. These are attributed to ${ }^{4} \mathrm{~T}_{1 \mathrm{~g}}(\mathrm{~F}) \rightarrow{ }^{4} \mathrm{~T}_{1 \mathrm{~g}}(\mathrm{~F})$, and ${ }^{4} T_{1 g}(F) \rightarrow{ }^{4} A_{2 g}(F)$ and $n \rightarrow \pi^{*}$ transition originated from the FAHP. These bands support the octahedral geometry for the Co(II) complex (Ballhausen, C.J., 1979). The Mn(II) complex exhibits strong band appearing at $440 \mathrm{~nm}$ may be due to the FAHP absorption peak. In the visible region the complex shows a weak absorption 561nm due to the overlapping of spin forbidden d-d transition with the intra ligand absorption (Lever, A.B.P., 1984).

\section{${ }^{1}$ H NMR Spectral data:-}

In the ${ }^{1} \mathrm{H}$ NMR spectrum of $\mathrm{Zn}$ (II) complex the triplet observed between $\delta 6.32-6.49 \mathrm{ppm}$ corresponds to the proton in the fifth position of the pyridine ring. Two doublets at $\delta 6.65-6.81 \mathrm{ppm}$ corresponds to the proton present in the fourth position of the furfuryl ring. Two doublets between $\delta 6.83-6.97 \mathrm{ppm}$ corresponds to the pyridine hydrogen present in the fourth position. The two doublets at $\delta 6.90-7.02 \mathrm{ppm}$ also correspond to pyridine hydrogen. Two doublets at $\delta 7.41-7.50 \mathrm{ppm}$ correspond to the furfuryl hydrogen at third position. A doublet at $\delta 7.86-7.89 \mathrm{ppm}$ is due to furfuryl hydrogen at fifth position. A singlet at $\delta 9.27 \mathrm{ppm}$ corresponds to azomethine hydrogen. The solubility of FAHP is less than the desired level in common deutrated solvents; so we couldn't obtain its NMR spectrum. The proton NMR spectrum of the complex is given in fig: 1 . 


\section{ESR Spectral data:-}

The X-band ESR spectra of the Cu(II) complex in DMF solution at liquid nitrogen temperature was recorded. The spectrum shows four well resolved peaks of low intensities in low field region and one at high field region. The ESR spectral data of the complex is given in Table-3. The $g$ values are calculated. The $g_{\square}$ and $g_{\perp \text { values indicate that the }}$ unpaired electron is localized in the $\mathrm{d}_{x-y}^{2}{ }^{2}$ orbital of the $\mathrm{Cu}$ (II) ion (Chandra, S.,2009). The inplane $\sigma$ bonding covalent parameter $\alpha^{2}$ calculated is less than unity indicates that the complex has some covalent character. The ESR spectrum of the complex in DMF solution at LNT is given in fig: 2.

\section{Mass spectral data:-}

The mass spectrum of Zn(II) complex of FAHP were recorded on FTMS- ESI Mass Spectrometer. The base peak observed at $\mathrm{m} / \mathrm{z} 353$ corresponds [ $\mathrm{M}+\mathrm{Na}$ ] species. This peak undoubtedly says that the molecular ion corresponds for the peak is $\left.\left[\mathrm{Zn}(\mathrm{FAHP})(\mathrm{Ac}) \mathrm{H}_{2} \mathrm{O}\right)\right]^{+}$, whose $\mathrm{m} / \mathrm{z}$ is 330 . The peak due to deprotonated FAHP is found at $\mathrm{m} / \mathrm{z} 187$, $\left[\right.$ FAHP] ${ }^{+}$. The mass spectra of FAHP and the $\mathrm{Zn}(\mathrm{II})$ complex are shown in fig: 3 \& fig: 4

Based on the physico chemical analysis the structure proposed for the ligand is shown in fig:5.

\section{Antimicrobial studies:-}

The invitro biological activity of the investigated Schiff base FAHP and its selected metal complexes were screened against the bacterial strains Escherichia coli and Staphylococcus aureus and fungi stains Aspergillus niger and Candida albicans. The results of the investigations account for the antipathogenic behaviour of the compounds. The investigation data of the compounds are summarized in Tables 4 and 5 and antimicrobial activity of FAHP and complexes are shown in figs: 6 and 7.

\section{Antioxidant studies:-}

The antioxidant activity of FAHP and the Mn(II) complex are studied by DPPH assay. It is a widely used method to evaluate antioxidant activities, in a relatively short time compared to other methods (Ceyhan, G., et al., 2011) DPPH radical contains an odd electron responsible for absorbance at $517 \mathrm{~nm}$. When the reaction between antioxidant molecule and DPPH takes place, the scavenging of radical by hydrogen or electron donation results. This cause a decrease of the absorbance of the DPPH radical and it is visually noticeable from purple to yellow. The results are shown in Table-6. These values indicate that $\left[\mathrm{Mn}(\mathrm{FAHP})(\mathrm{Ac})\left(\mathrm{H}_{2} \mathrm{O}\right)_{2}\right]$ have noticeable activity compared to the standard.

Table 1:- Analytical data of the FAHP complexes

\begin{tabular}{|l|l|l|l|l|l|l|l|l|}
\hline Complex & Metal\% & Anion\% & C\% & N\% & H\% & $\mu$ eff & \multicolumn{2}{|l|}{ Conductivity } \\
\cline { 5 - 9 } & & & & & & & Methanol & DMF \\
\hline & 19.7 & - & 43.8 & 8.7 & 3.2 & - & 24.61 & 14.90 \\
& $(19.9)$ & & $(43.9)$ & $(8.5)$ & $(3.2)$ & & & \\
\hline & 20.7 & 11.5 & 39.4 & 9.3 & 3.2 & & 17.80 & 13.32 \\
{$\left[\mathrm{CuLClH}_{2} \mathrm{O}\right]$} & $(20.9)$ & $(11.7)$ & $(39.6)$ & $(9.2)$ & $(3.3)$ & 2.3 & & \\
\hline & 12.4 & - & 51.5 & 12.2 & 4.1 & 2.9 & 19.46 & 15.33 \\
{$\left[\mathrm{NiL}_{2}\left(\mathrm{H}_{2} \mathrm{O}\right)_{2}\right]$} & $(12.5)$ & & $(51.5)$ & $(12.0)$ & $(4.2)$ & & & \\
\hline & 16.2 & - & 33.1 & 11.5 & 3.7 & 4.6 & 20.83 & 18.27 \\
{$\left[\mathrm{CoLNO}_{3}\left(\mathrm{H}_{2} \mathrm{O}\right)_{3}\right]$} & $(16.3)$ & & $(33.3)$ & $(11.6)$ & $(3.8)$ & & & \\
\hline & 15.5 & - & 40.5 & 7.7 & 4.7 & 5.6 & 21.12 & 11.31 \\
{$\left[\mathrm{MnL}(\mathrm{Ac})\left(\mathrm{H}_{2} \mathrm{O}\right)_{3}\right]$} & $(15.5)$ & & $(40.7)$ & $(7.9)$ & $(4.8)$ & & & \\
\hline
\end{tabular}

$\mathrm{L}=$ FAHP

$\mathrm{Ac}=$ Acetate

Table 2:- Important IR spectral bands of FAHP and its complexes

\begin{tabular}{|c|c|c|c|c|c|c|}
\hline $\mathbf{L}$ & {$\left[\mathrm{ZnL}(\mathbf{A C}) \mathbf{H}_{2} \mathbf{O}\right]$} & {$\left[\mathrm{CuLCl}\left(\mathrm{H}_{2} \mathrm{O}\right)\right]$} & {$\left[\mathrm{Ni}(\mathbf{L})_{2}\left(\mathrm{H}_{2} \mathrm{O}\right)_{2}\right]$} & {$\left[\mathrm{CoL}\left(\mathrm{NO}_{3}\right)\left(\mathrm{H}_{2} \mathrm{O}\right)_{3}\right]$} & {$\left[\mathrm{MnL}(\mathbf{A C})\left(\mathrm{H}_{2} \mathrm{O}\right)_{3}\right]$} & Assignments \\
\hline- & 3453 & 3420 & 3354 & 3318 & 3374 & $v_{\mathrm{OH} \text { (water) }}$ \\
\hline 3252 & - & - & - & - & - & $v_{\mathrm{OH} \text { phenolic }}$ \\
\hline 2925 & 2915 & 2895 & 2892 & 2917 & 2905 & $v_{\mathrm{C}-\mathrm{H}}$ strech \\
\hline 1557 & 1532 & 1534 & 1536 & 1533 & 1532 & $v_{\mathrm{C}=\mathrm{N}}$ \\
\hline- & 1598 & - & - & - & 1596 & $v_{\mathrm{COO}}$ (asy) \\
\hline- & 1406 & - & - & - & 1404 & $v_{\mathrm{COO}}(\mathrm{sy})$ \\
\hline
\end{tabular}


Table 3:- Spin Hamiltonian parameters of the copper (II)complex

\begin{tabular}{|l|l|l|l|l|l|l|}
\hline Compound & $\mathrm{A}_{\|}$ & $g_{\|}$ & $g_{\perp}$ & $g_{\text {ave }}$ & $\mathrm{G}$ & $\alpha^{2}$ \\
\hline$\left[\mathrm{Cu}(\mathrm{FAHP}) \mathrm{Cl}\left(\mathrm{H}_{2} \mathrm{O}\right)\right]$ & 150.00 & 2.45 & 2.04 & 2.07 & 6.66 & 0.93 \\
\hline
\end{tabular}

Table 4 :- Antibacterial activity of FAHP and its complexes

\begin{tabular}{|l|l|l|}
\hline Compound & $\begin{array}{l}\text { Escherichia } \\
\text { coli }\end{array}$ & $\begin{array}{l}\text { Staphylococcus } \\
\text { aureus }\end{array}$ \\
\hline Gentamycin & $2.1 \mathrm{~cm}$ & $2.1 \mathrm{~cm}$ \\
\hline FAHP & $1.5 \mathrm{~cm}$ & $1.5 \mathrm{~cm}$ \\
\hline$\left[\mathrm{Ni}(\mathrm{FAHP})_{2}\left(\mathrm{H}_{2} \mathrm{O}_{2}\right]\right.$ & $1.4 \mathrm{~cm}$ & $1.6 \mathrm{~cm}$ \\
\hline$\left[\mathrm{Co}(\mathrm{FAHP}) \mathrm{NO}_{3}\left(\mathrm{H}_{2} \mathrm{O}\right)_{3}\right]$ & $1.3 \mathrm{~cm}$ & $1.2 \mathrm{~cm}$ \\
\hline$\left[\mathrm{Mn}(\mathrm{FAHP}) \mathrm{AC}_{2}\left(\mathrm{H}_{2} \mathrm{O}\right)_{3}\right]$ & $1.5 \mathrm{~cm}$ & $1.7 \mathrm{~cm}$ \\
\hline
\end{tabular}

Table 5:- Antifungal activity of FAHP and its complexes

\begin{tabular}{|l|l|l|}
\hline Compound & $\begin{array}{l}\text { Aspergillus } \\
\text { niger }\end{array}$ & $\begin{array}{l}\text { Candida } \\
\text { albicans }\end{array}$ \\
\hline Clotrimazole & $1.5 \mathrm{~cm}$ & $1.9 \mathrm{~cm}$ \\
\hline FAHP & $\mathrm{NZ}$ & $1.0 \mathrm{~cm}$ \\
\hline$\left[\mathrm{Ni}(\mathrm{FAHP})_{2}\left(\mathrm{H}_{2} \mathrm{O}_{2}\right]\right.$ & $\mathrm{NZ}$ & $1.0 \mathrm{~cm}$ \\
\hline$\left[\mathrm{Co}(\mathrm{FAHP}) \mathrm{NO}_{3}\left(\mathrm{H}_{2} \mathrm{O}\right)_{3}\right]$ & $2.1 \mathrm{~cm}$ & $1.2 \mathrm{~cm}$ \\
\hline$\left[\mathrm{Mn}(\mathrm{FAHP}) \mathrm{AC}_{2}\left(\mathrm{H}_{2} \mathrm{O}\right)_{3}\right]$ & $\mathrm{NZ}$ & $\mathrm{NZ}$ \\
\hline
\end{tabular}

Table 6:- Percentage inhibition of antioxidant activity of FAHP and Mn(II) complex Optical density of control at $517 \mathrm{~nm}$ is 0.389

\begin{tabular}{|l|l|l|}
\hline Sample concentration $(\boldsymbol{\mu g} / \mathbf{m l})$ & OD at $\mathbf{5 1 7} \mathbf{n m}$ & \% inhibition \\
\hline FAHP & & \\
\hline 12.5 & 0.353 & 9.25 \\
\hline 25 & 0.309 & 20.56 \\
\hline 50 & 0.140 & 64.01 \\
\hline 100 & 0.113 & 70.95 \\
\hline 200 & 0.102 & 73.77 \\
\hline$\left[\mathbf{M n}(\mathbf{F A H P}) \mathbf{A C}\left(\mathbf{H}_{\mathbf{2}} \mathbf{O}\right)_{\mathbf{3}}\right]$ & & \\
\hline 12.5 & 0.276 & 29.04 \\
\hline 25 & 0.269 & 30.84 \\
\hline 50 & 0.261 & 32.90 \\
\hline 100 & 0.252 & 35.21 \\
\hline 200 & 0.189 & 51.41 \\
\hline
\end{tabular}

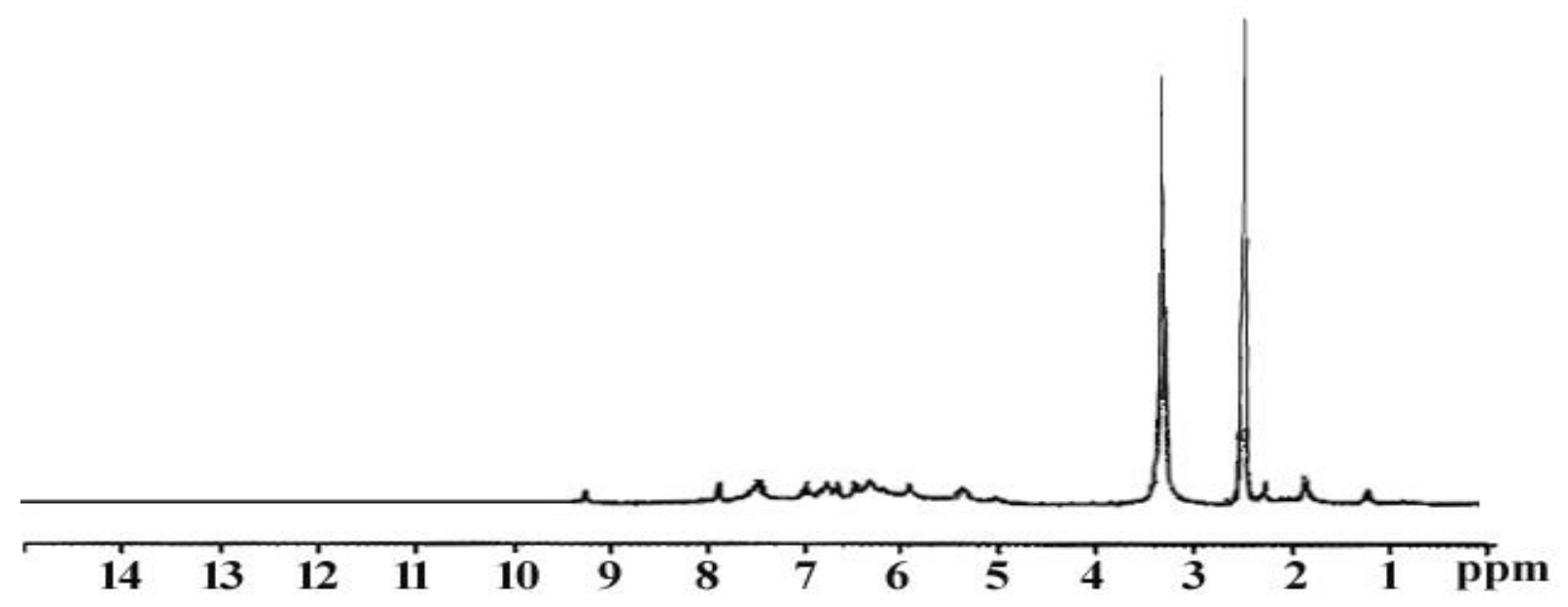

Fig: 1:- Proton NMR Spectrum of $\left[\mathrm{Zn}(\mathrm{FAHP})(\mathrm{Ac}) \mathrm{H}_{2} \mathrm{O}\right]$ 


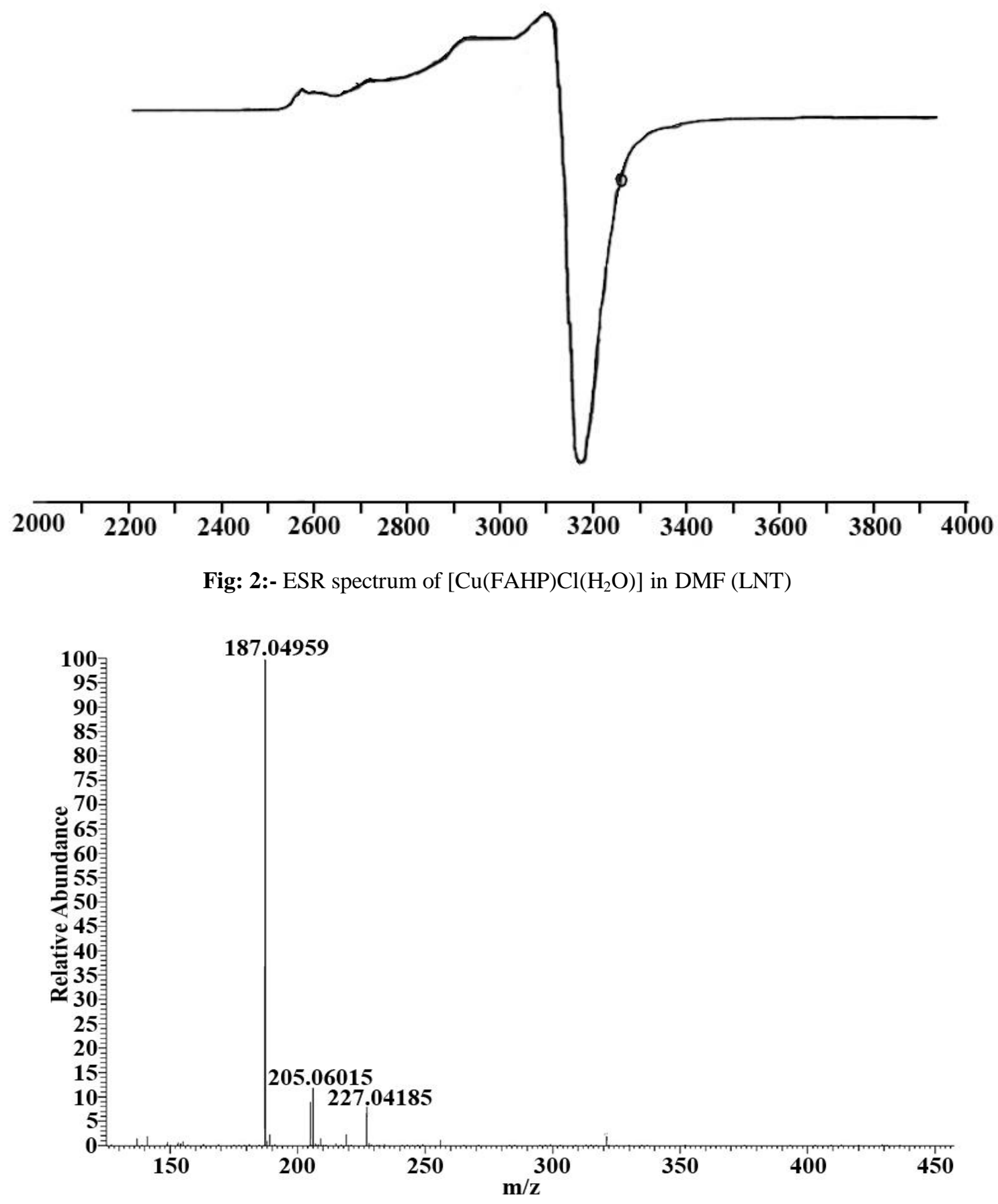

Fig: 3:- Mass spectrum of FAHP 


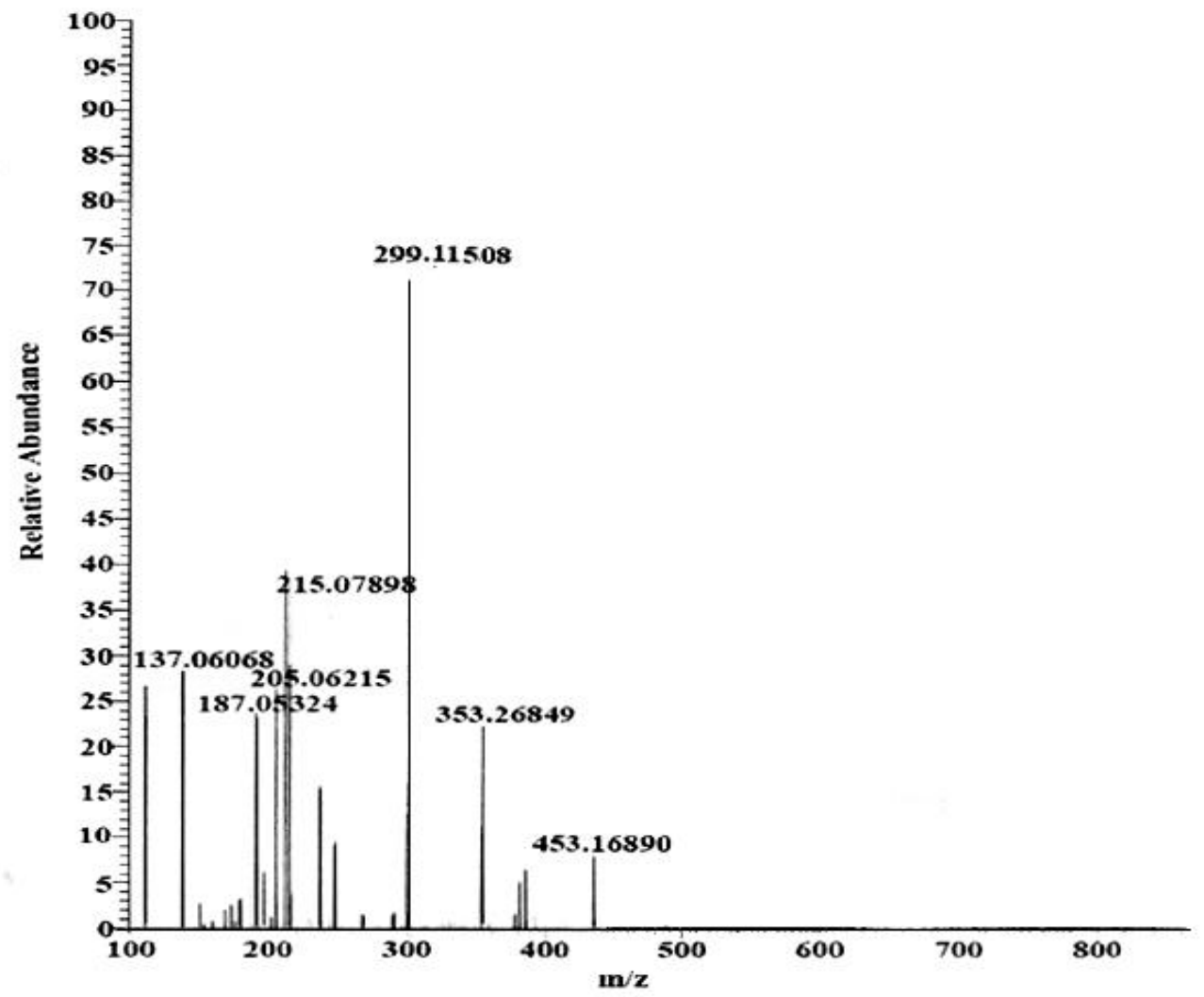

Fig: 4:- Mass spectrum of $\left[\mathrm{Zn}(\mathrm{FAHP})(\mathrm{Ac}) \mathrm{H}_{2} \mathrm{O}\right]$

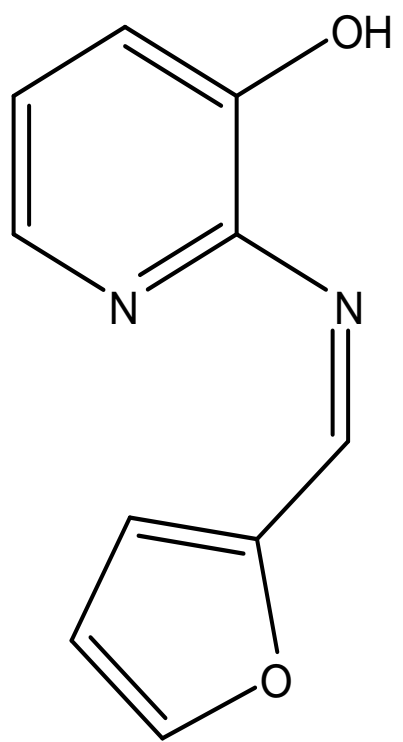

Fig:5:- proposed structure of FAHP 

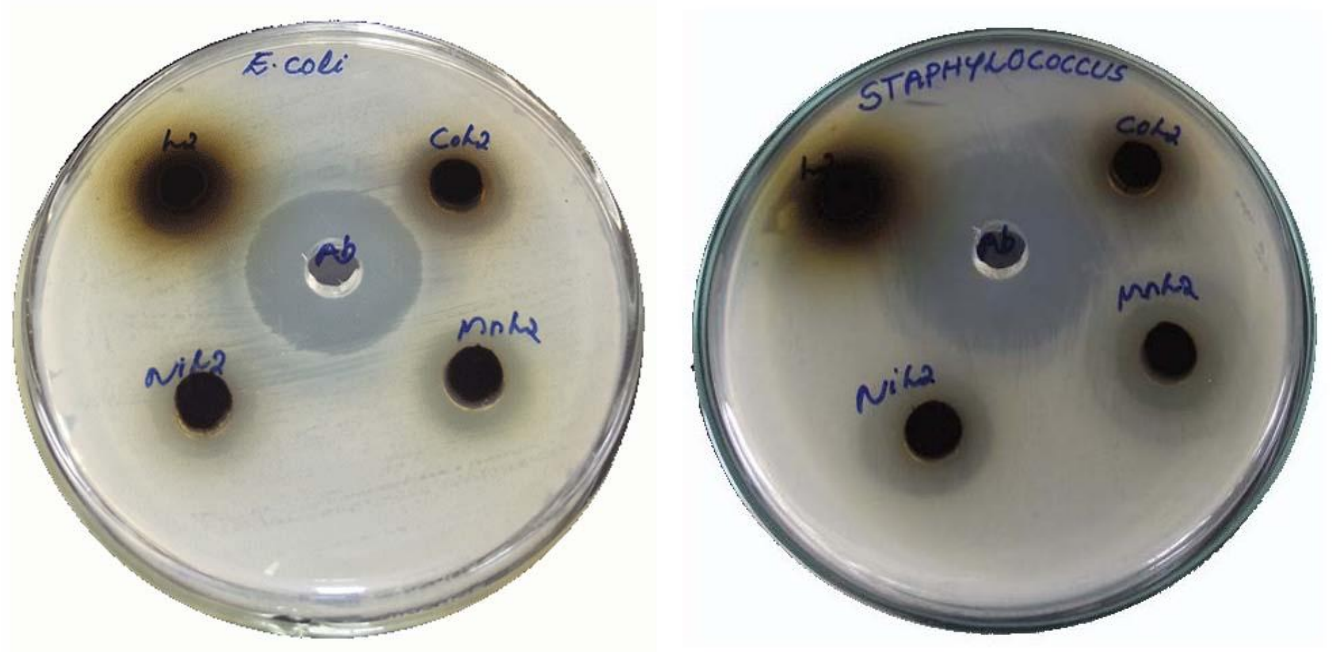

Fig: 6:- Antibacterial activity of FAHP and its complexes
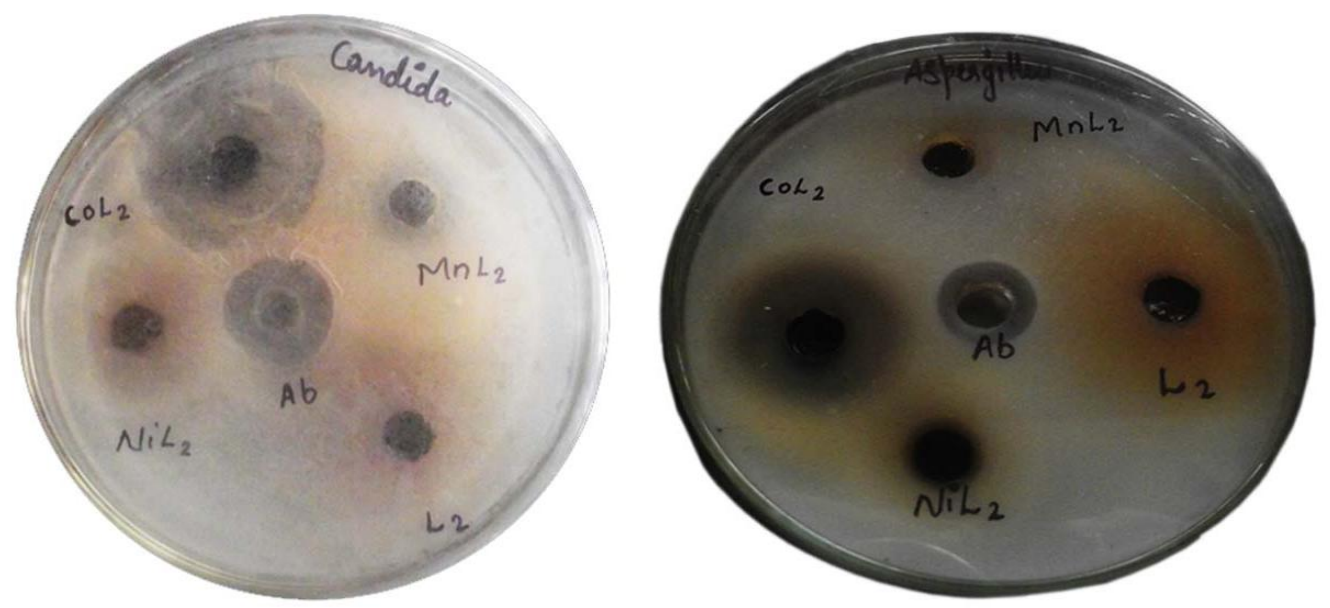

Fig: 7:- Antifungal activity of FAHP and its complexes.

\section{Conclusion:-}

The present work includes the synthesis and characterization of [2-(furan-2-yl methyleneamino)pyridine-3-ol] and its five complexes with the metal ions $\mathrm{Mn}$ (II), $\mathrm{Co}(\mathrm{II}), \mathrm{Ni}(\mathrm{II}), \mathrm{Cu}$ (II) and $\mathrm{Zn}(\mathrm{II})$ using various physico chemical and spectral analyses. All the complexes show non electrolytic behavior. The metal to ligand ratio is 1:1 in all complexes except in $\left[\mathrm{Ni}(\mathrm{FAHP})_{2}\left(\mathrm{H}_{2} \mathrm{O}\right)_{2}\right.$ ] where it is 1:2. Based on the spectroscopic data and other analytical evidences square planar geometry is proposed for $\mathrm{Cu}$ (II) complex and tetrahedral geometry is proposed to $\mathrm{Zn}$ (II) . The reamaing complexes have octahedral geometry. The Schiff base and the metal complexes screened for antibacterial activity show comparable values. The $\mathrm{Mn}$ (II) complex shows noticeable antioxidant activity to the standard.

\section{Acknowledgments:-}

We are thankful to the Department of Chemistry, University College, Trivandrum for instrumental facilities under FIST DST and STIC, Cochin University and Technology for analytical facilities. 


\section{References:-}

1. Asiri , A.M.; Khan, S.A., (2010) Synthesis and antibacterial activities of some novel Schiff bases derived from aminophenazone. Molecules, 15, 6850-6858.

2. Ballhausen, C.J; (1979); 'Molecular Electronic structure of Transition Metal Complexes', McGraw Hill, New York,

3. Ceyhan, G.; Celik, C.; Urus, S.; Demirtas, I.; Elmastas, M.; Tumer, M., (2011), Antioxidant, electrochemical, thermal, antimicrobial and alkane oxidation properties of tridentate Schiff base ligands and their metal complexes. Spectrochim. Acta Part A Mol. Biomol. Spectrosc. 81, 184-188.

4. Chandra, S.; Jain, D.; Sharma, A.K.; (2009), EPR, mass, electronic, IR spectroscopic and thermal studies of bimetallic copper(II) complexes with tetradentate ligand, 1,4-diformyl piperazine bis(carbohydrazone), Spectrochim Acta Part A, 71, 1712-1719.

5. Geary, W. J., (1971), The use of conductivity measurements in organic solvent for the characterization of coordination compounds, Cood. Chem. Rev., 7, 81-122.

6. Lever, A. B. P; (1968),' Inorganic Electronic Spectroscopy Elsevier, Amsterdam,

7. Lever, A.B.P; (1984). 'Inorganic Electronic Spectroscopy,'Elsevier, Amsterdam,

8. Narag, K.,K., and Singh, V.P; (1993), Synthesis, Characterization and Biological Activity of Cobalt (II), Nickel(II), Copper(II) and Zinc(II) Chloride Complexes withValeraldehydeBenzoylhydrazone and Valeraldehyde Isonicotinoylhy Drazone, Synth. React. Met. Org. Chem., 23, 607-627.

9. Rajendra. K. Jain; Mishra, A.P.; (2010), Microwave synthesis, spectroscopic, thermal and biological significance ofsome transition metal complexes containing heterocyclic ligands, J. Chem. Pharm. Res., 2, 51-61.

10. Rajendra .K. Jain; Anand.P. Mishra; (2012), Microwave synthesis, spectral, thermal, 3D Molecular modeling analysis and antimicrobial activities of some transition metal complexes of Schiff basesderived from5-brmo salicylaldehyde, J.Seb.Chem. Soc.77(8), 1013-1029.

11. Rosu, T.; Pahontu, E.; Maxim, C.; Georgescu, R.; Stanica, N.; Almajan, G.L.; Gulea, A., (2010), synthesis, characterization and antibacterial activity of some new complexes of $\mathrm{Cu}(\mathrm{II}), \mathrm{Ni}(\mathrm{II}), \mathrm{VO}(\mathrm{II}), \mathrm{Mn}$ (II) with Schiff base derived from 4-amino-2,3-dimethyl-1-phenyl-3-pyraolin-5-one. Polyhedron, 29, 757-766.

12. Weissberger,A.; Proskauer, P.S.; Hiddick, J.A.; Troops, (1956),B.E., 'Organic Solvents, Interscience, New York,

13. Zhao, X.; Lee, P.P.F.; Yan, Y. K.; Chu, C.K., (2007), Synthesis, crystal structures and cytotoxicities of some transition metal complexes with $\mathrm{N}-[2-\{$ (pyridin-2-ylmethylidene) amino\}ethyl $]$ acetamide J. Inor. Biochem., 101, 321-328. 